\title{
Important Key Process Simulations in the Field of Steel Metallurgy
}

\author{
A. Ludwig', C. M. G. Rodrigues' ${ }^{1}$, Z. Zhang ${ }^{1}$, H. Zhang ${ }^{1}$, E. Karimi-Sibaki ${ }^{1,2}$, H. Barati ${ }^{1,3}$, A. Vakhrushev ${ }^{1,2}$, \\ M. Al-Nasser ${ }^{1,2}, M^{2}$ Wu $^{1}$, and A. Kharicha ${ }^{1,2}$ \\ 1Department Metallurgy, University of Leoben, Leoben, Austria \\ ${ }^{2}$ Christian Doppler Laboratory for 'Magnetohydrodynamical applications in Metallurgy', Department Metallurgy, \\ University of Leoben, Leoben, Austria \\ ${ }^{3} \mathrm{~K} 1-\mathrm{Met}$, University of Leoben, JKU Linz, Leoben, Linz, Austria
}

Received October 22, 2021; accepted November 24, 2021; published online December 15, 2021

\begin{abstract}
During the last decade, the chair for 'Simulation and Modelling of Metallurgical Processes' (SMMP) has worked on different metallurgical processes with the highlights of the following five industrial relevant topics: (i) modelling the as-cast structures of large steel castings; (ii) exploring the formation mechanisms of macrosegregation; (iii) describing magnetohydrodynamic and electrochemical phenomena in remelting processes, (iv) understanding how solidification and flow can be influenced by magnetohydrodynamics during steel continuous casting; and $(v)$ describing nozzle clogging in steelmaking processes. In this contribution, the main achievements from the group on the above five topics are briefly described.
\end{abstract}

Keywords: Steel casting, Macrosegregation, Remelting processes, Continuous casting, Nozzle clogging

Wichtige Prozesssimulationen in der Stahl Metallurgie

Zusammenfassung: In den letzten zehn Jahren hat sich der Lehrstuhl für Simulation und Modellierung Metallurgischer Prozesse mit verschiedenen metallurgischen Prozessen beschäftigt und einen Schwerpunkt auf folgende fünf industrierelevante Themen gelegt: (i) Modellierung des Gefüges bei großen Stahlgussteilen; (ii) Beschreibung der Entstehungsmechanismen von Makroseigerungen; (iii) Beschreibung magnetohydrodynamischer und elektrochemischer Vorgänge bei Umschmelzverfahren; (iv) Untersuchungen zur Beeinflussung der Erstarrung und der Strömung mittels Magnetohydrodynamik; und (v) Modellierung des Tauchrohrverstopfung bei der Stahlherstellung.

\author{
A. Ludwig $(\square)$ \\ Department Metallurgy, \\ University of Leoben, \\ Leoben, Austria \\ andreas.ludwig@unileoben.ac.at
}

In diesem Beitrag werden die wesentlichen Ergebnisse zu den erwähnten fünf Themenkomplexen beschrieben.

Schlüsselwörter (deutsch): Stahlguss, Makroseigerung, Umschmelzprozesse, Strangguss, Tauchrohrverstopfung

\section{Introduction}

Since the foundation of the chair for 'Simulation and Modelling of Metallurgical Processes' (SMMP) in 2003, many industrial relevant research projects have been worked on. Important to mention is the establishment of three Christian-Doppler Laboratories over the years (2004-2011: 'Multi-phase simulations of metallurgical processes', A. Ludwig, 2011-2018: 'Process simulation of solidification and melting', M. Wu, 2018-2025: 'Magnetohydrodynamical applications in Metallurgy', A. Kharicha). Together with achievements from other projects, the expertise that was gained in these CD-laboratories had led to the definition of the five key process simulation activities that are presented here. Although the authors prefer to give an overview about a specific topic by including the state-ofthe-art and thus the work of others, we were asked to give solely an overview about highlight activities of the SMMP group.

\section{Modelling the As-cast Structure in Large Steel Casting}

An industrial steel casting might easily weigh from several tons up to one hundred. They are produced either discontinuously as large ingots or continuously by forming slabs or billets. All these products reveal a certain ascast structure which can be classified as columnar dendritic, equiaxed dendritic, or of mixed type. Due to the large ton- 
nage, the castings may take days or weeks to solidify; several transport and accompanying redistribution phenomena can happen during this time, e.g. by crystal motion and melt convection. Understanding these phenomena is one of our key interest.

Our research has the potential to optimize the casting parameters by controlling the as-cast structure and minimizing the macrosegregation in industry castings (ingots and continuous casting of steel, DC casting of non-ferrous alloys). It may aid industry to design new solidification processes (e.g. semi-continuous casting of steel). It will also be important as it allows an integration into industry 4.0 as an important part of the virtual/intelligent manufacturing.

The primary aims and objectives of this research field are:
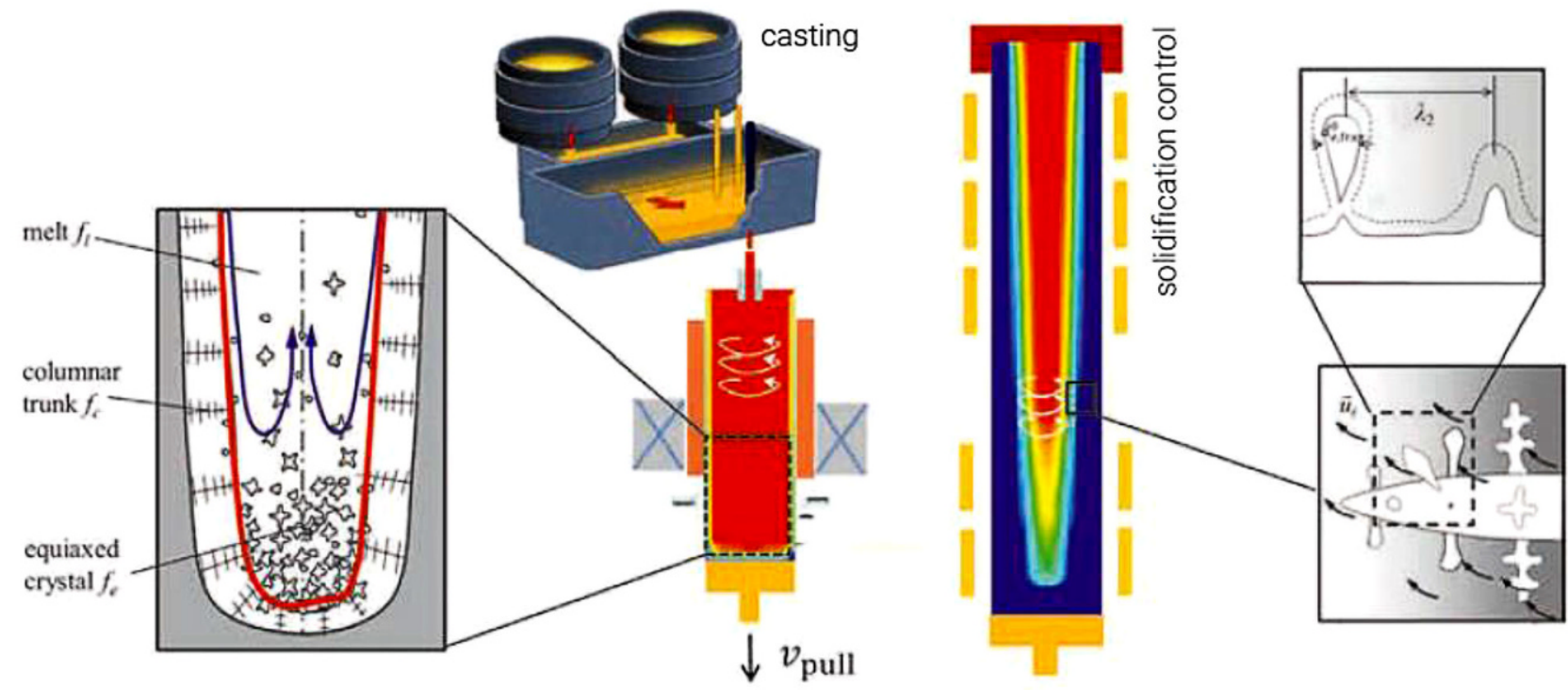

a

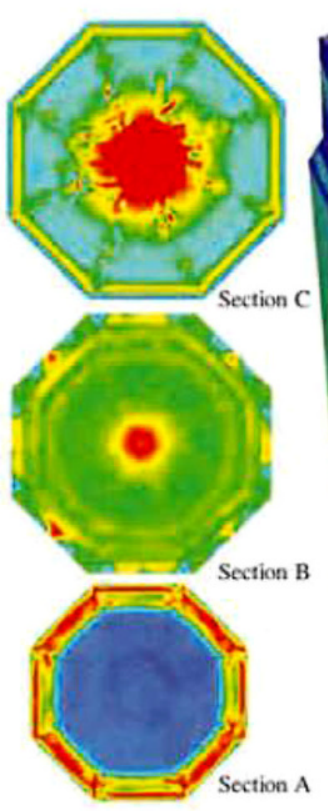

b



c

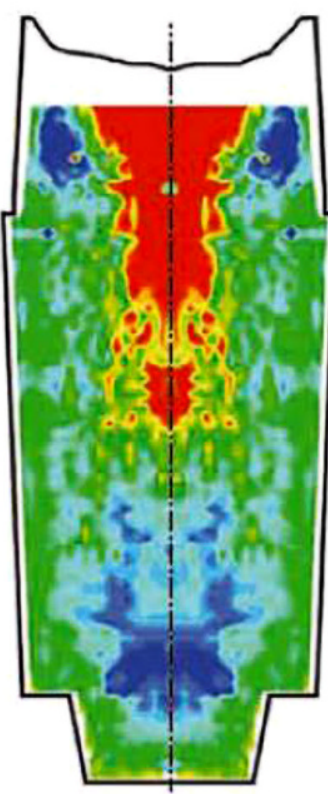

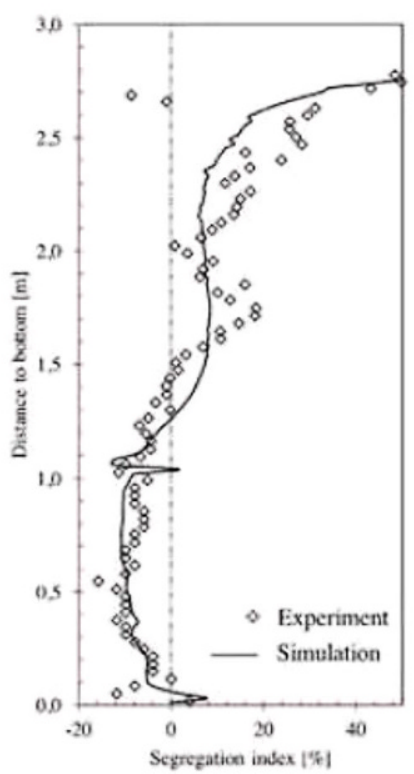

d

Fig. 1: a Schematics of semi-continuous casting process (SCC), and the principle to control the as-cast structure. The mixed columnar-equiaxed solidification model is extended to investigate the mould filling (casting) and solidification processes including the origin of equiaxed crystals due to EMSinduced crystal fragmentation during SCC. b, c, d Numerical simulation of as-cast structure and macrosegregation in a 36 -ton ingot. b Numerically-simulated segregation maps in different vertical and horizontal sections; $\mathbf{c}$ the macrosegregation map of the as-cast ingot as measured in the longitudinal section [Personal communication with. Hofa Shen, Tsinghua Univ., China, 2017]; d comparison of the numerically-simulated macrosegregation profiles along the centreline. (b-d: reprint from ref. [1] with permission) 
- To understand the formation of the as-cast structure of steel castings that are manufactured at an industrial scale;

- To develop a numerical model for the mixed columnar-equiaxed solidification considering columnar-toequiaxed-transition (CET) and macrosegregation;

- To model the electromagnetic stirring during continuous casting, and its effect on the as-cast structure (crystal fragmentation);

- To apply the numerical model to aid industry to optimize the casting processes (ingot, continuous casting);

- To apply the numerical model to aid industry to design a new casting process (semi-continuous casting);
- To further evaluate the numerical model by comparing the modelling results with laboratory experiments and plant trials.

Examples of recent achievements are given in Fig. 1. Further details on that topic can be found in ref. [1-7].

\section{Formation Mechanisms of Macro- segregation}

The compositional heterogeneity at the scale of industry casting is called macrosegregation. It is caused by the fact
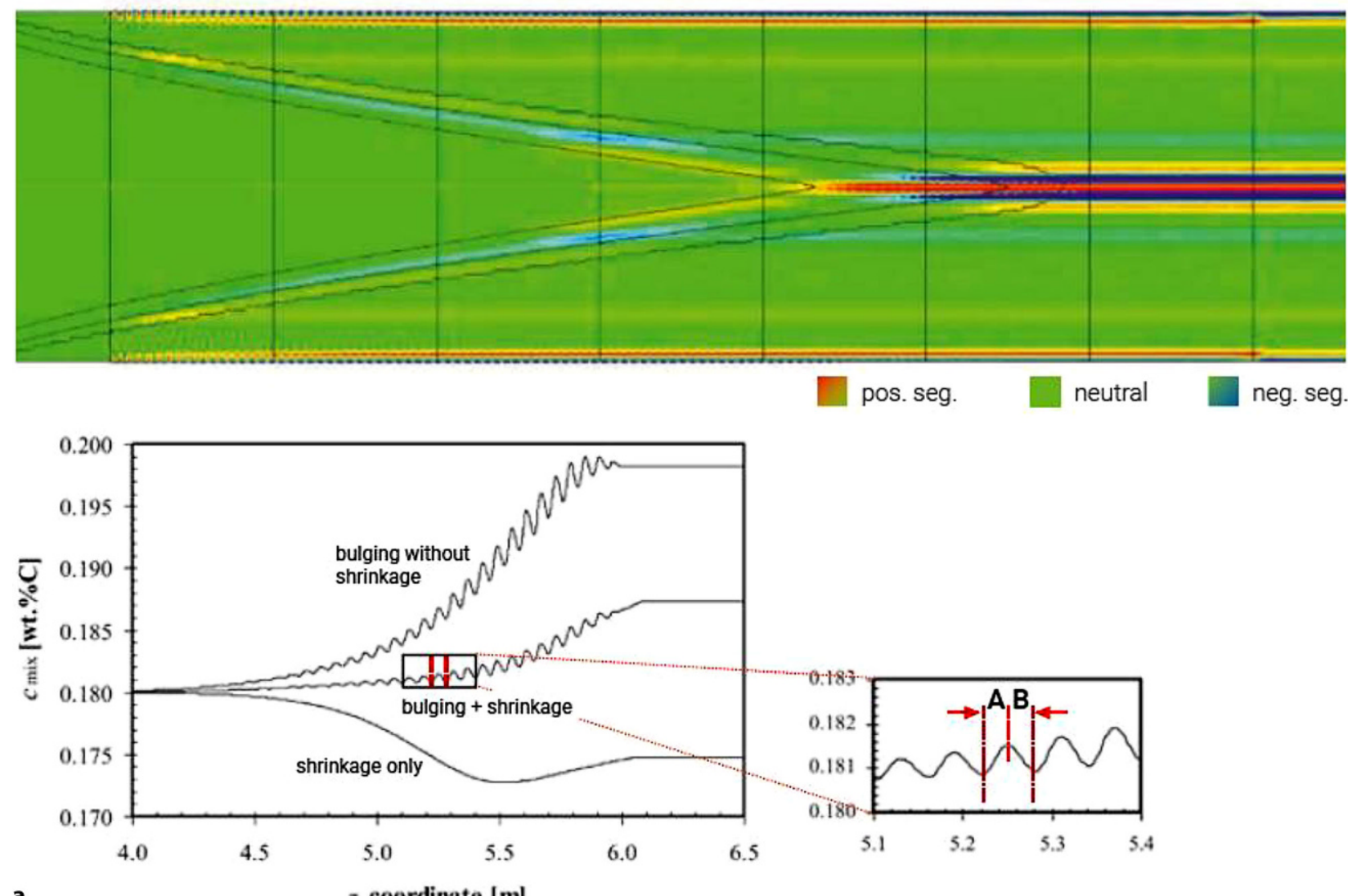

a

$z$ coordinate $[\mathrm{m}]$

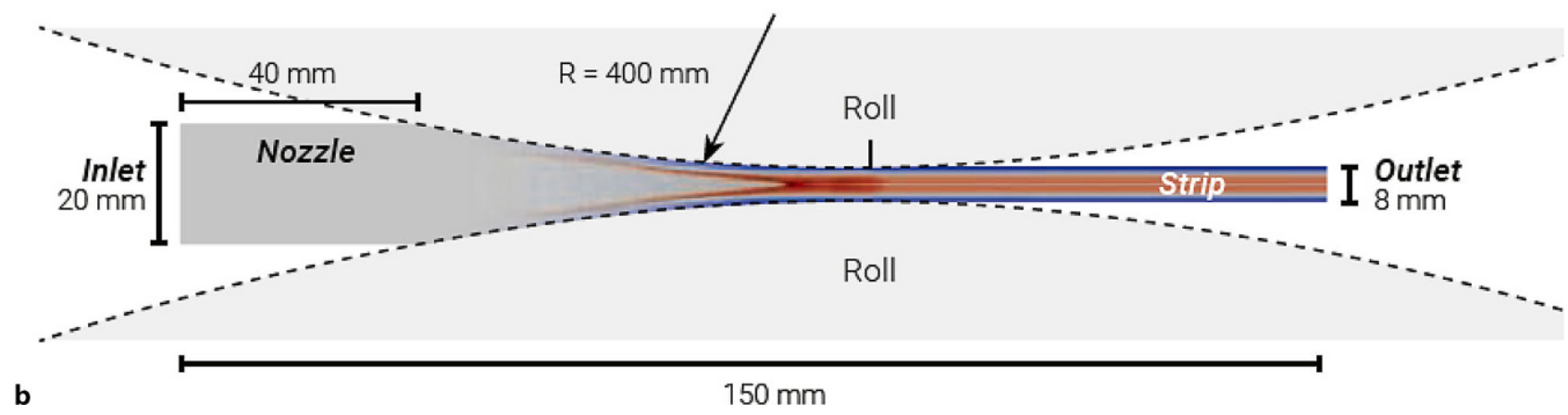

Fig. 2: a Predicted macrosegregation during bulging of a steel slab (for postprocessing the results lengths are scaled 1:10). (Diagram) Comparison of centreline segregation for three different cases corresponding to solidification of the horizontal model steel slab: (i) shrinkage only, (ii) bulging only, and (iii) combined effect of shrinkage and bulging. b Predicted macrosegregation during twin-roll casting of Al-4wt.\%Cu. The viscoplastic high-solid fraction regions are heavily deformed during rolling, resulting in a densification of the dendritic network and thus in a pressing out of segregated liquid. (b: reprint from open access ref. [10]) 
that usually solidifying crystals do not incorporate all alloying elements and thus the remaining liquid gets more and more enriched in solute. This is called (micro-)segregation. If the flow now redistributes this segregated liquid to some other location, the concentration, and with that the microstructure, will become inhomogeneous. As many different mechanisms for a relative movement between crystal and liquid exist (e.g. thermal or solutal buoyancy, sedimentation, deformation, etc.), the occurrence of macrosegregation and also the measures that can be taken to avoid their formation are numerous.

This researchfield has the potential to extend our understanding of macrosegregation formation, to develop industrial relevant strategies for reducing macrosegregation, and to refine the solidification models (source codes) and to integrate them into industry 4.0 as an important part of virtual/intelligent manufacturing.

The primary aims and objectives of this research field are:

- to use multiphase solidification models and to study macrosegregation mechanisms as caused by:

- thermo-solutal convection;

- crystal sedimentation;

- feeding flow due to solidification shrinkage;

- forced flow such as electro-magnetic stirring;

- mechanical deformation of the mushy zone;

- Marangoni convection.

- to evaluate numerical models against different theoretical models or experimental benchmarks:

- laboratory experiments;

- Flemings theory;

- industry castings.

- to apply numerical models for different industry processes (ingots, continuous castings of steel, and direct chill casting of copper/aluminium).
Examples of recent achievements are given in Fig. 2. Further details on that research field can be found in ref. [1, 8-16].

\section{Magnetohydrodynamic and Electro- chemical Phenomena in Remelting Processes}

In order to decrease $\mathrm{CO}_{2}$ production, the developments of a new generation of metallurgical processes using electric currents are planned by the world leading industrial groups. Strong currents will be transferred through plasma and high temperature electrolytes to achieve the production of new metallic alloys. The fundamental knowledge built by our research has the potential to solve complex physical, technical, and design issues that can arise during these crucial developments.

From daily experience, we know that, with a strong electric current, materials can be heated and even melted. However, when applied on an industrial scale, the fact that most materials are opaque causes a major problem because important details on what happens remain hidden. Here, the numerical process simulation acts as visualiser and allows to zoom-in when necessary. Even simulations with hypothetic properties or unusual process conditions can be done and thus hints in which direction a process optimisation might be possible can be gained. As an example, we have worked on understanding and optimising the Electro-slag remelting (ESR) process. This is a process where an extremely high electric current heats a liquid slag that then melts an electrode so that the alloy is then drop-wise crossing the liquid slag and forming a new liquid pool that finally solidifies with an improved quality.

The corresponding aims and objectives of this research field are:
Fig. 3: The electroslag remelting (ESR) process, composed of slag, mould, ingot, and electrode, is simulated considering the turbulent flow in the slag and melt pool. Exemplary numerical results are shown here as a mean thermal field and b mean velocity field
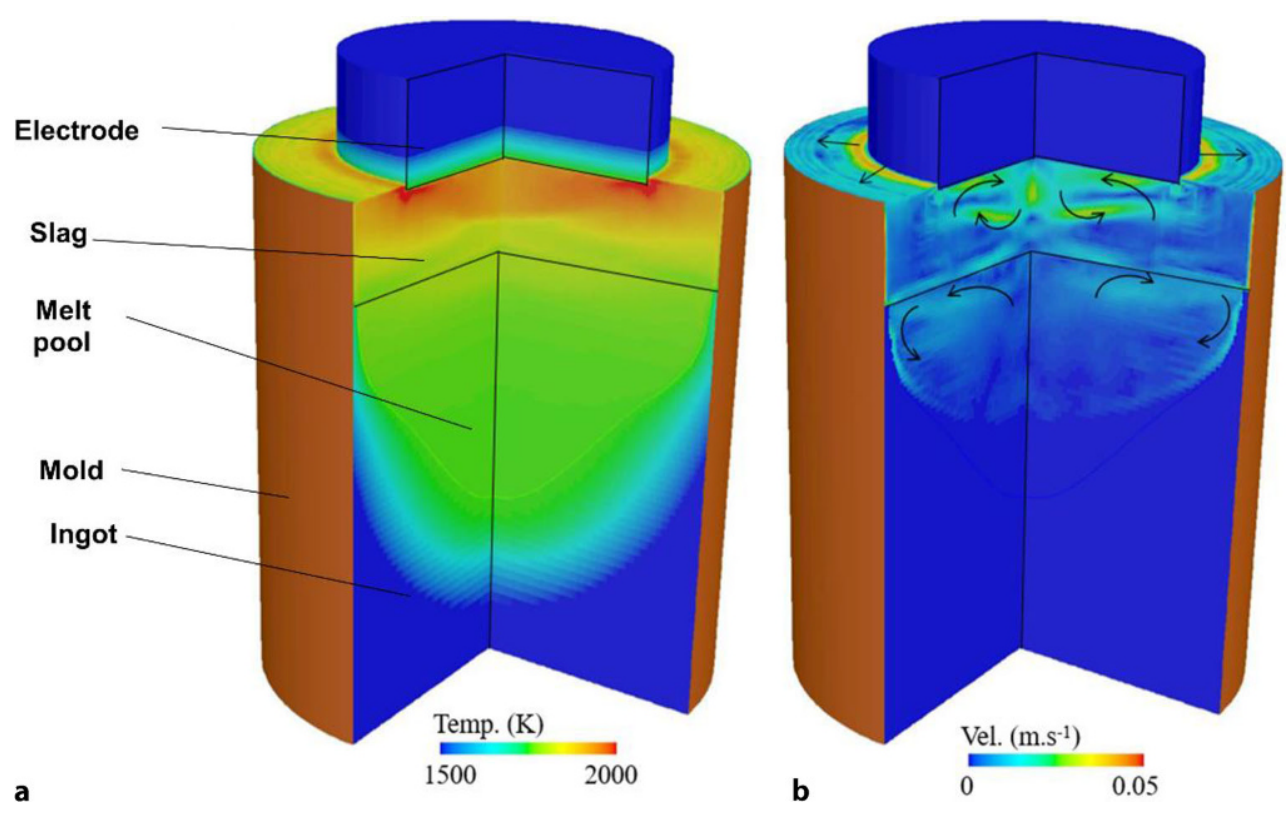
- to understand the interaction between phase distribution and magnetohydrodynamics when strong electric currents are applied;

- to predict the electrical current path in the presence of strong spatial and temporal variation of electric conductivity;

- to solve process instabilities and predict the formation of defects in the electroslag remelting process (ESR) and vacuum arc remelting (VAR) process;

- to understand electrochemical aspects of the ESR process;

- to predict the thermal and solidification characteristics during remelting of different metallic alloys;

- to explore the origin of the coherent arc behaviour in the VAR process;

- building a numerical model to predict the behaviour of an electric arc inside a furnace accounting for magnetohydrodynamics, flow dynamics, compressibility, turbulence and thermal fields.

Examples of recent achievements are given in Fig. 3. Further details on that research field can be found in ref. [17-25].

\section{Steel Continuous Casting: Solidification, Flow, and Magnetohydrodynamics}

For more than three decades, numerical simulations of steel continuous casting considering solidification and flow have widely spread. They are valuable for the design and optimization of the casting process, especially for thin slab casting (TSC). Interaction between flow and solidification, which is quite intensive in TSC, and electromagnetic braking used to stabilise the flow are up-to-date topics where numerical models are recently under development.
In both fields, we have obtained successful developments that are now applied under productive conditions.

Our scientific investigations provide the theoretical basis for innovative control techniques which will lead to growing productions rates by increasing the casting speed while keeping the quality. Thus, large energy savings by casting at lower super heat and promoting $\mathrm{CO}_{2}$ reduction will be achieved. The methodology developed opens the possibility to apply electromagnetic fields to other metallurgical and semiconductor industries.

The corresponding aims and objectives of this research field are:

- multiphase phenomena modelling during continuous casting (CC): turbulent flow, shell growth, non-metallic inclusions (NMI) and bubbles motion, meniscus behaviour, etc.;

- model development of the turbulent flow under the applied magnetic field considering the Lorentz force;

- coupled numerical simulation of the solidification during $\mathrm{CC}$ with the magnetohydrodynamic (MHD) effects from the electromagnetic brake (EMBr)

- models' verification against analytical solutions, experimental data and existing numerical results;

- influence of the casting and $\mathrm{EMBr}$ conditions on the CC mould flow pattern, the shell thickness, meniscus temperature, slag band stability, and NMI removal efficiency;

- application of the results of the numerical studies for a real industrial process with optimization aims regarding the cast products quality.

Examples of recent achievements are given in Fig. 4. Further details on that research field can be found in ref. [26-35].

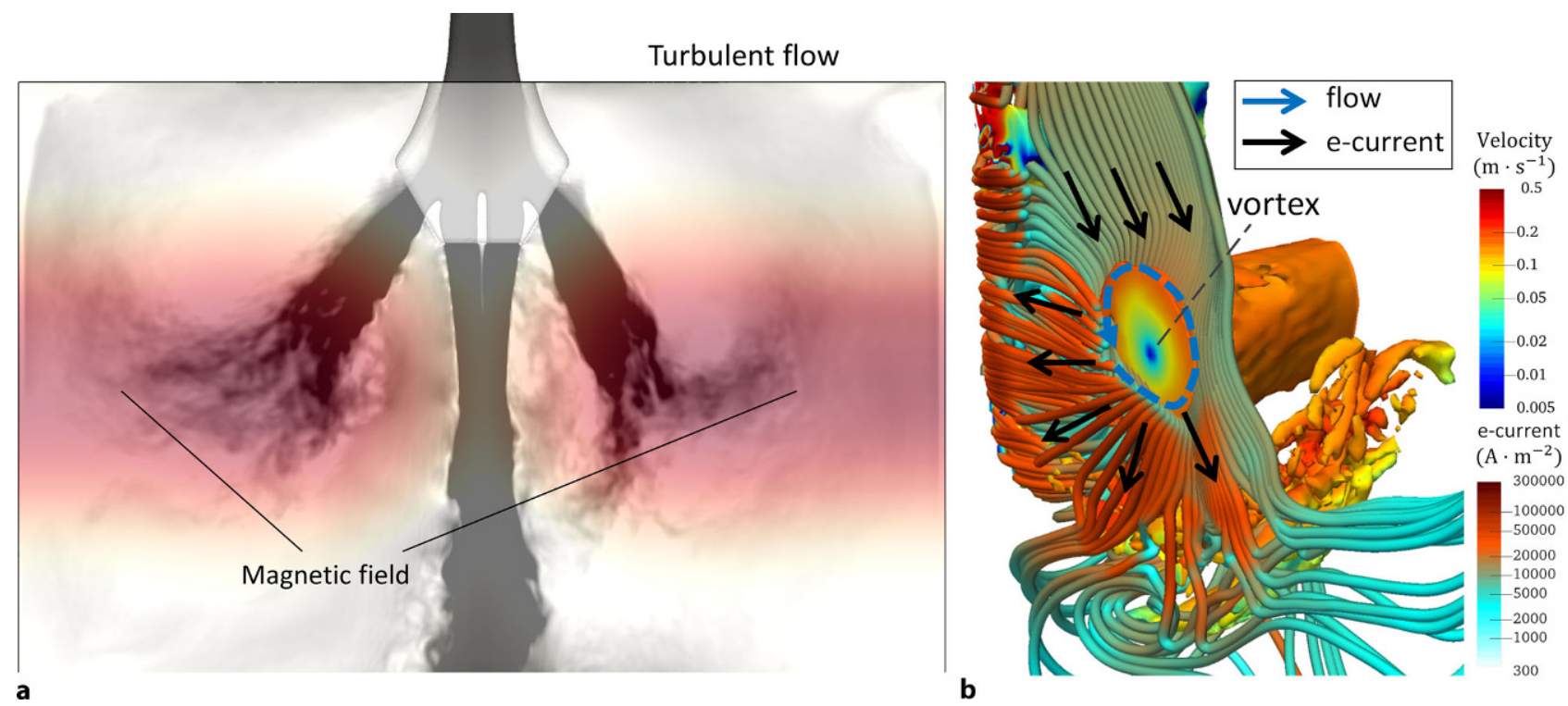

Fig. 4: a Modelling of turbulent melt flow during thin slab continuous casting of steel. The width ofthe funnel-shaped mould is around $1.5 \mathrm{~m}$. The final slab has a thickness of around $15 \mathrm{~cm}$; b flow pattern under applied electro-magnetic break and the electric current interaction with a vortex structure. (reprint from open access ref. [33]) 


\section{Nozzle Clogging in Steelmaking Processes}

Although named "continuous", steel continuous casting is not really a process without stops. Sooner or later the submerged entry nozzle (SEN) has to be replaced by a fresh one as it gets clogged with time. The reason for that is that the SEN material interacts with the steel and with the nonmetallic particle herein leading to a growing layer of oxides forming at the inner SEN wall. This so-called clogging phenomenon is a major problem for the steel industry and has been significantly reducing their productivity.

Therefore, this research field has the potential to optimize the casting parameters by minimizing the clogging tendency during the continuous casting of steel. It will also be important as it allows an integration into industry 4.0 as an important part of virtual/intelligent manufacturing. The developed numerical model can also be extended to investigate the clogging/fouling phenomenon (deposition and accumulation of solid suspended particles on the fluid passage) in other engineering processes, such as in heat exchangers, petrochemical industry, automotive industry food production, and pharmaceutical industries.

The corresponding aims and objectives of this research field are:

- to develop a transient clogging model considering key physical/chemistry mechanisms:

- origin of the non-metallic inclusions (NMIs);

- transport of NMIs by the molten steel of high turbulence, and the effect of Ar gas;

- behaviour of NMls in the boundary layer of the nozzle wall (refractory);

- adhesion mechanism of NMls on the nozzle wall and the effect of nozzle refractory materials;
Fig. 5: a A transient nozzle clogging model is developed and used to simulate a laboratory experiment (simulator of nozzle clogging: Comdicast $A B$, Sweden) with a purpose to validate the numerical model. b, $\mathbf{c}$ Evolution of clogging in the nozzle. b View of the clog region from the vertical section and a cross-section A-A of the nozzle; c Zoomed view of the fl ow streamlines and a partially clogged section at 200 s. The clogged section is shown in yellow. The magnitude of the flow velocity is shown in a colour scale along the streamlines. (a reprint with permission from Kojola et al., Ironmak. Steelmak. 38, 81-89 (2011), except the simulation picture on the left, $\mathbf{b}$ reprint from ref. [36] with permission)

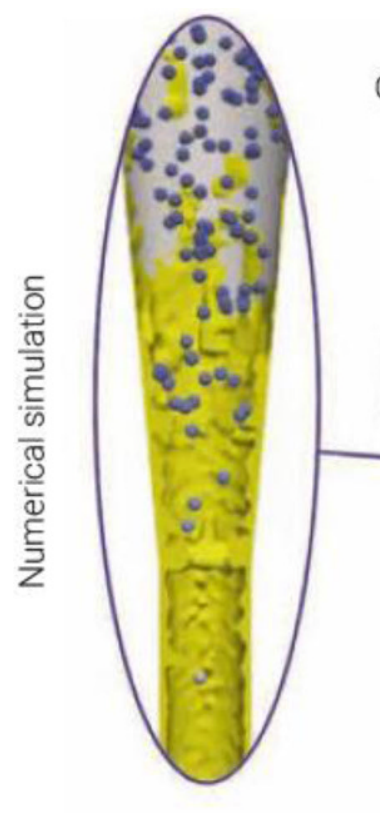

\section{Clogging phenomenon in a steel transport nozzle}
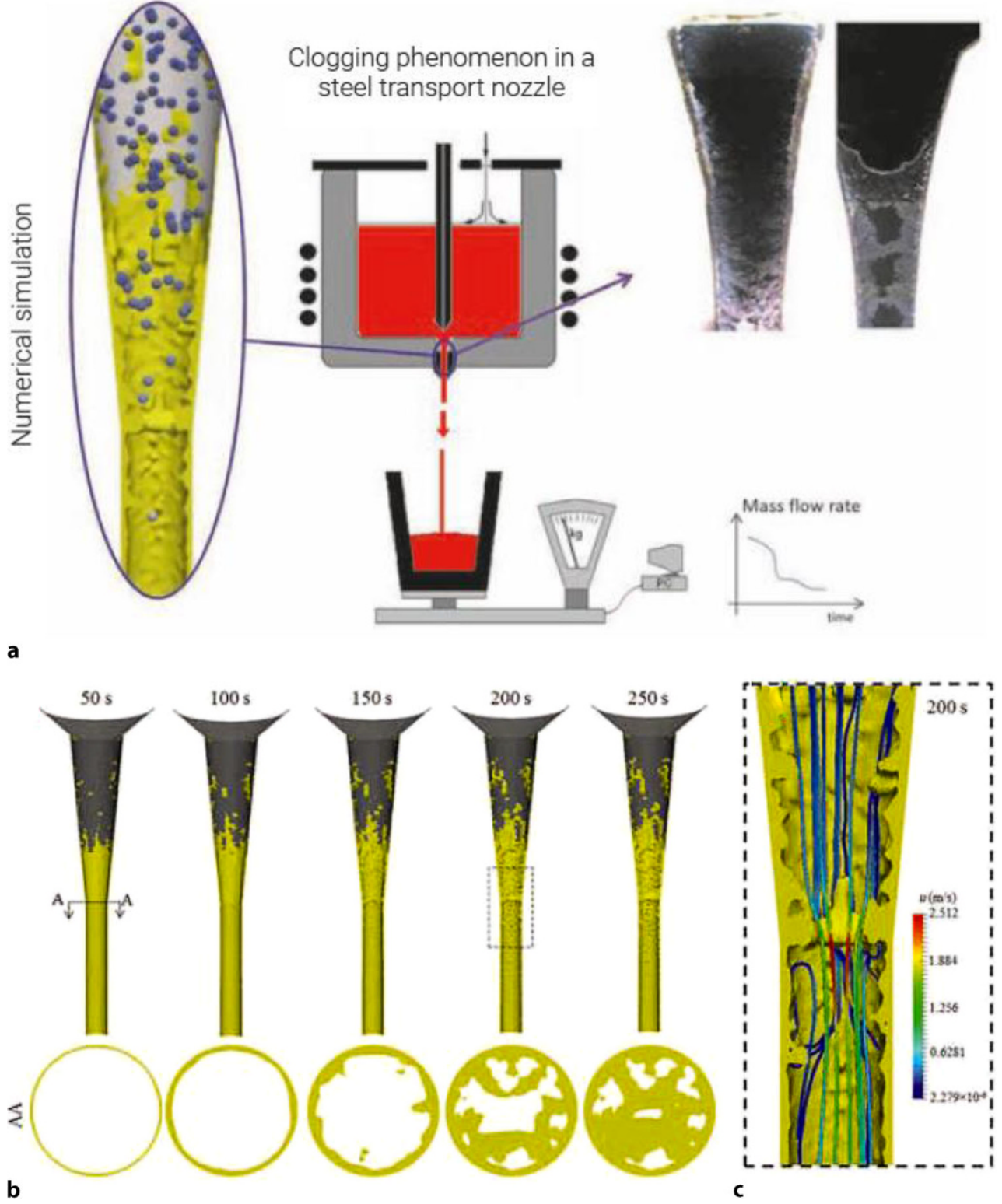

c 
- growth of the clog front and its interaction with the turbulent melt flow;

- flow and possible solidification of molten steel in the clog region;

- fragmentation/detachment of the clog.

- evaluation of the numerical model against available laboratory/industry experiments;

- achievement of a fundamental understanding about the nozzle clogging in steelmaking processes, and aid the industry to optimize the process parameters.

Examples of recent achievements are given in Fig. 5. Further details on that research field can be found in ref. [36-42].

Funding. Open access funding provided by Montanuniversität Leoben.

Open Access This article is licensed under a Creative Commons Attribu tion 4.0 International License, which permits use, sharing, adaptation, distribution and reproduction in any medium or format, as long as you give appropriate credit to the original author(s) and the source, provide a link to the Creative Commons licence, and indicate if changes were made. The images or other third party material in this article are included in the article's Creative Commons licence, unless indicated otherwise in a credit line to the material. If material is not included in the article's Creative Commons licence and your intended use is not permitted by statutory regulation or exceeds the permitted use, you will need to obtain permission directly from the copyright holder. To view a copy of this licence, visit http://creativecommons.org/licenses/by/4.0/.

\section{References}

1. Wu, M., Ludwig, A., Kharicha, A.: Simulation of as-cast steel ingot, a review. Steel Res. Int. 89, 1700037 (2018)

2. Zheng, Y., Wu, M., Kharicha, A., Ludwig, A.: Incorporation of fragmentation into a volume average solidification model. Model. Simul. Mater. Sci. Eng. 26, 15004 (2018)

3. Ludwig, A., Wu, M., Kharicha, A.: On macrosegregation. Met. Mater. Trans. A 46, 4854-4867 (2015)

4. Wu, M., Ludwig, A., Kharicha, A.: A four phase model for the macrosegregation and shrinkage cavity during solidification of steel ingot. Appl. Math. Model. 41, 102-120 (2017)

5. Wu, M., Zheng, Y., Kharicha, A., Ludwig, A.: Numerical analysis of as-cast structure, macrosegregation and shrinkage cavity in steel ingots: case study of a 36 tons' ingot. In: 7th Int. Conf. on Mod. \& Simul. of Metall. Processes in Steelmaking (STEELSIM2017) Qingdao, China. pp. 129-132. (2017)

6. Zheng, Y., Wu, M., Kharicha, A., Ludwig, A.: Concept of semi-continuous casting (SCC) for large steel strand: a numerical study. In: China Symposium on Sustainable Steelmaking Technology Tianjin, China, Oct. 24-26, 2018. pp. 355-357. (2018). Proceedings in electric device

7. Li, J., Wu, M., Kharicha, A., Ludwig, A.: The predication of macrosegregation in a 2.45 tons' steel ingot with a mixed columnar-equiaxed three phases model. Int. J. Heat Mass Transf. 72, 668-679 (2014)

8. Rodrigues, C.M.G., Ludwig, A., Kharicha, A., Wu, M.: Modelling of the twin-roll casting process: transition from casting to rolling. Trans. Indian Inst. Met. 71, 2639-2643 (2018)

9. Rodrigues, C.M.G., Ludwig, A., Wu, M., Kharicha, A., Vakhrushev, A.: A comprehensive analysis of macrosegregation formation during twin-roll casting. Met. Mater. Trans. B 50, 1334-1350 (2019)

10. Rodrigues, C.M.G., Ludwig, A., Wu, M., Kharicha, A., Vakhrushev, A.: Two-phase viscoplastic model for the simulation of twin roll casting. J. Mater. Process. Tech. 286, 116814 (2020)

11. Zheng, Y., Wu, M., Karimi-Sibaki, E., Kharicha, A., Ludwig, A.: Use of a mixed columnar-equiaxed solidification model to analyses the formation of as-cast structure and macrosegregation in a Sn-10 wt\%
Pb benchmark experiment. Int. J. Heat Mass Transf. 122, 939-953 (2018)

12. Wu, M., Domitner, J., Ludwig, A.: Using a two-phase columnar solidification model to study the principle of mechanical softreduction in slab casting. Met. Mater. Trans. A 43, 945-963 (2012)

13. Domitner, J., Wu, M., Kharicha, A., Ludwig, A., Kaufmann, B., Reiter, J., Schaden, T.: Modeling the effect of strand surface bulging and mechanical softreduction on the macrosegregation formation in steel continuous casting. Met. Mater. Trans. A 45, 1415-1434 (2014)

14. Wu, M., Zheng, Y., Kharicha, A., Ludwig, A.: Numerical analysis of macrosegregation in vertically solidified $\mathrm{Pb}$-Sn test castings-Part I: Columnar solidification. Comp. Mater. Sci. 124, 444-455 (2016)

15. Zheng, Y., Wu, M., Kharicha, A., Ludwig, A.: Numerical analysis of macrosegregation in vertically solidified $\mathrm{Pb}-\mathrm{Sn}$ test castings-Part II: Equiaxed solidification. Comp. Mater. Sci. 124, 456-470 (2016)

16. Ahmadein, M., Wu, M., Ludwig, A.: Analysis of macrosegregation formation and columnar-to-equiaxed transition during solidification of $\mathrm{Al}-4 \mathrm{wt} . \% \mathrm{Cu}$ ingot using a 5-phase model. J. Cryst. Growth 417, 65-74 (2015)

17. Karimi-Sibaki, E., Kharicha, A., Bohacek, J., Wu, M., Ludwig, A.: A parametric study of the vacuum arc remelting (VAR) process: effects of arc radius, side arcing, and gas cooling. Met. Mater. Trans. 51, 222-253 (2019)

18. Karimi-Sibaki, E., Kharicha, A., Bohacek, J., Wu, M., Ludwig, A. Contribution of an electro-vortex flow to primary, secondary, and tertiary electric current distribution in an electrolyte. J. Electrochem. Soc. 165, E604-15 (2018)

19. Karimi-Sibaki, E., Kharicha, A., Wu, M., Ludwig, A., Bohacek, J.: Confrontation of the Ohmic approach with the ionic transport approach for modeling the electrical behavior of an electrolyte. Ionics 24, 2157-2165 (2018)

20. Karimi-Sibaki, E., Kharicha, A., Wu, M., Ludwig, A., Bohacek, J. Modeling electrochemical transport of ions in the molten $\mathrm{CaF} 2-\mathrm{FeO}$ slag operating under a DC voltage. Appl Math Comput 357, 357-373 (2018)

21. Kharicha, A., Karimi-Sibaki, E., Wu, M., Ludwig, A., Bohacek, J.: Review on modeling and simulation of electroslag remelting. Steel Res. Int. 89(1700100), 1-20 (2018)

22. Karimi-Sibaki, E., Kharicha, A., Wu, M., Ludwig, A., Bohacek, J.: Toward modeling of electrochemical reactions during Electroslag remelting (ESR) process. Steel Res. Int. 88(1700011), 1-8 (2017)

23. Kharicha, A., Wu, M., Ludwig, A., Karimi-Sibaki, E.: Simulation of the electrical signal during the formation and departure of droplets in the electro slag remelting process. Met. Mater. Trans. B 47, 1427-1434 (2016)

24. Karimi-Sibaki, E., Kharicha, A., Bohacek, J., Wu, M., Ludwig, A On validity of axisymmetric assumption for modeling an industrial scale electroslag remelting process. Adv. Eng. Mater. 18, 224-230 (2016)

25. Karimi-Sibaki, E., Kharicha, A., Bohacek, J., Wu, M., Ludwig, A.: A dynamic mesh-based approach to model melting and shape of an ESR electrode. Met. Mater. Trans. 46, 4854-4867 (2015)

26. Vakhrushev, A., Wu, M., Ludwig, A., Tang, Y., Hackl, G., Nitzl, G.: Numerical investigation of shell formation in thin slab casting of funnel-type mould. Met. Mater. Trans. B 45, 1024-1037 (2014)

27. Wu, M., Vakhrushev, A., Ludwig, A., Kharicha, A.: Influence of forced convection on solidification and remelting in the developing mushy zone. lop Conf. Series: Mater. Sci. Eng. 117, 12045 (2016)

28. Vakhrushev, A , Wu, M. Ludwig, A Nitzl, G., Tang, Y, Hackl, G. Wincor, R.: A water experiment benchmark to evaluate numerical models for the motion of particles in continuous casting tundish. Steel Res. Int. 87(1600276), 1-13 (2016)

29. Liu, Z., Vakhrushev, A., Wu, M., Karimi-Sibaki, E., Kharicha, A., Ludwig, A., Li, B.: Effect of an electrically-conducting wall on transient magnetohydrodynamic flow in a continuous casting mold with an electromagnetic brake. Metals 8(609), 1-14 (2018)

30. Vakhrushev, A., Kharicha, A, Wu, M. Ludwig, A, Nitzl, G., Tang, Y., Hackl, G., Watzinger, J., Rodrigues, C.: On modelling viscoplastic behavior of the solidifying shell in the funnel-type continuous casting mold. lop Conf. Series: Mater. Sci. Eng 529, 12081 (2019) 
31. Liu, Z., Li, B., Vakhrushev, A., Wu, M., Ludwig, A.: Physical and numerical modeling of exposed slag eye in continuous casting mold using Euler-Euler approach. Steel Res. Int. 90(18020117), 1-10 (2019)

32. Liu, Z., Vakhrushev, A., Wu, M., Kharicha, A., Ludwig, A., Li, B.: Scale-adaptive simulation of transient two-phase flow in continuous casting mold. Met. Mater. Trans. B 50, 543-554 (2019)

33. Vakhrushev, A., Kharicha, A., Liu, Z., Wu, M., Ludwig, A., Nitzl, G., Tang, Y., Hackl, G., Watzinger, J.: Electric current distribution during electromagnetic brake in continuous casting. Met. Mater. Trans. B 51, 2811-2828 (2020)

34. Vakhrushev, A., Kharicha, A., Karimi-Sibaki, E., Wu, M., Ludwig, A., Nitzl, G., Tang, Y., Hackl, G., Watzinger, J., Eckert, S.: Generation of reverse meniscus flow by applying an electromagnetic brake. Met. Mater. Trans. B 52, 3193-3207 (2021)

35. Vakhrushev, A., Kharicha, A., Karimi-Sibaki, E., Wu, M., Ludwig, A., Tang, Y., Hackl, G., Nitzl, G., Watzinger, J., Bohacek, J.: On modelling parasitic solidification due to heat loss at submerged entry nozzle region of continuous casting mold. Metals 11, 1375 (2021)

36. Barati, H., Wu, M., Kharicha, A., Ludwig, A.: A transient model for nozzle clogging. Powder Technol 329, 181-198 (2018)

37. Barati, H., Wu, M., Kharicha, A., Ludwig, A.: Calculation accuracy and efficiency of a transient model for submerged entry nozzle clogging. Met. Mater. Trans. B 50B, 1428-1443 (2019)

38. Wu, M., Barati, H., Kharicha, A., Ludwig, A.: Using a numerical model to study the transient clogging phenomena in SEN during continuous casting of steel. In: Proc. of STEESIM (8th Int. Conf. on Mod. \& Simul. of Metall. Processes in Steelmaking) Toronto, Canada, Aug. 13-15, 2019. pp. 664-667. (2019)

39. Barati, H., Wu, M., Kharicha, A., Ludwig, A.: Discussion on possible solidification during SEN clogging in steel continuous casting. In: Roosz, A. (ed.) Proc. of SG'13 (7th Int. Conf. on Solidification and Gravity) Miskolc, Hungary, Sept. 3-6, 2018. pp. 144-149. (2018)

40. Wu, M., Barati, H., Kharicha, A., Ludwig, A.: Mathematical modeling of the early stage of clogging of the SEN during continuous casting of Ti-ULC steel. In: Proc. of STEESIM (9th Int. Conf. on Mod. \& Simul. of Metall. Processes in Steelmaking) Virtual conference, Oct. 5-7, 2021. pp. 430-434. (2021)

41. Barati, H., Wu, M., Holzmann, T., Kharicha, A., Ludwig, A.: Simulation of non-metallic inclusion deposition and clogging of nozzle. In: Nastac, L., Pericleous, K., Sabau, A., Zhang, L., Thomas, B. (eds.) Proc. CFD Model. Simul. in Mater. Processing, TMS 2018 Phoenix AZ, USA, Mar. 11-15. 2018. pp. 149-158. (2018) https://doi.org/10. 1007/978-3-319-72059-3_15

42. Barati, H., Wu, M., Kharicha, A., Ludwig, A.: Assessment of difference turbulence models for the motion of non-metallic inclusion in induction crucible furnace. lop Conf. Series: Mater. Sci. Eng. 143(012036), 365-371 (2016). Proc. of LMPC (Liquid Metal Processing \& Casting Conference, Sept. 20-24, 2015, Leoben, Austria), Edited by Kharicha A., Ward R.M., Holzgruber H. and Wu M.

Publisher's Note. Springer Nature remains neutral with regard to jurisdictional claims in published maps and institutional affiliations. 